\title{
Componentes de produção de genótipos de feijão-caupi irrigados com água salina
}

\section{Production components of bean-cowpea genotypes irrigated with saline water}

\author{
Kyonelly Queila Duarte Brito ${ }^{1}$, Ronaldo do Nascimento ${ }^{2}$, Joyce Edja Aguiar dos Santos ${ }^{3}$, Ivis Andrei Campos e Silva ${ }^{4}$, \\ Gideilton José Dantas Junior ${ }^{5}$
}

Resumo: O feijão-caupi (Vigna unguiculata L. Walp), é uma leguminosa, cultivada em diversas regiões principalmente no semiárido, torna-se uma opção para a região nordeste, uma vez que pode servir como alternativa de fonte de renda aos pequenos e médios produtores. Nesse sentido, objetivou-se avaliar as características produtivas de diferentes genótipos de feijão-caupi irrigados com água salina. A pesquisa foi desenvolvida em casa de vegetação da Universidade Federal de Campina Grande. Utilizou-se o delineamento experimental inteiramente casualizado, em esquema fatorial 2 x 5 com 4 repetições, sendo os tratamentos compostos de dois níveis de condutividade elétrica da água(A1 - água de abastecimento com $0,8 \mathrm{dSm}^{-1}$ e A2 - solução salina 4,8 dSm${ }^{-1}$ ) e cinco genótipos de feijão-caupi (G1 - MNC04-762F-9, G2 - MNC04-762F-3, G3 MNC04-762F-21, G4 - MNC04-769F-62 e G5 - MNC04-765F-153). Iniciou-se aplicação das águas salinizadas aos 12 dias após o semeio (DAS). As variáveis analisadas foram o número de vagens por planta (NVP), comprimento da vagem por planta (CVP), número de grãos por vagem (NGV), número de grãos por planta (NGP) e peso dos grãos por planta (PGP). Houve interação entre os fatores, Salinidade da água de irrigação e Genótipos de feijão-caupi, para a variável número de grãos por planta.

Palavras-chaves: Vigna unguicula L. Walp, salinidade, tolerância.

\begin{abstract}
Cowpea (Vigna unguiculata L. Walp) is a herbaceous legume, considered main vegetable protein source for lowincome families in Brazil. Grown in hot humid climates and semi-arid, it becomes an option for the northeast region, since it can serve as an alternative income source to small and medium producers. In this sense, the objective was to evaluate the production characteristics of cowpea genotypes irrigated with saline water. The treatments consisted of the combination of two factors: Irrigation Water Salinity (A1 - water supply with 0,8dSm-1 and A2 - saline solution $4.8 \mathrm{dSm}-1$ ) and cowpea genotypes (G1 - MNC04-762F -9, G2 - MNC04-762F-3 G3 - MNC04-762F-21 G4 - G5 and MNC04-769F-62 - MNC04765F-153). Combined factors, a completely randomized design, resulted in 10 treatments (2 levels of salinity x 5 genotypes) with four repetitions. The irrigation with saline water given to the 12 days after sowing (DAS). The variables were the number of pods per plant (NP), pod length per plant (PL), number of seeds per pod (SP), number of grains per plant (GP) and weight of grains per plant (WGP). The salinity of the irrigation water significantly reduced the productive characteristics of cowpea genotypes.
\end{abstract}

Key words: Vigna unguicula L. Walp, salinity, tolerance.

\footnotetext{
*Autor para correspondência

Recebido para publicação em 31/08/2015; aprovado em 20/09/2015

${ }^{1}$ Mestrando UAEAg/CTRN/UFCG. Campina Grande - PB. E-mail: queiladuarte@ hotmail.com

2 Professor Doutor UAEAg/CTRN/UFCG. Campina Grande - PB E-mail: ronaldo@ deag.ufcg.edu.br

${ }^{2}$ Mestrando, UAEAg/CTRN/UFCG. Campina Grande - PB. E-mail: joycedja@ @otmail.com

${ }^{3}$ Graduando, UAEAg/CTRN/UFCG. Campina Grande - PB. E-mail: ivisandrei@gmail.com

${ }^{4}$ Graduando, UAEAg/CTRN/UFCG. Campina Grande - PB. E-mail: gidedantas@ gmail.com
} 


\section{INTRODUÇÃO}

O feijão-caupi (Vigna unguiculata L. Walp), é uma planta leguminosa herbácea, pertencente à família Fabacea, originário da África, introduzida no Brasil no século XVI.

A cultura do feijão-caupi é tradicionalmente plantada no Nordeste brasileiro, vem se expandindo para outras regiões do Brasil, principalmente para o Centro-Oeste, em razão da sua ampla adaptabilidade às condições tropicais e ao baixo custo de produção, e em decorrência do intenso trabalho de melhoramento aplicado à cultura nos últimos 20 anos (NASCIMENTO, 2011).

A salinidade dos solos e das fontes hídricas em áreas agrícolas de todo o mundo tem gerado preocupação e comprometido o rendimento de diversas culturas. No Brasil, altas concentrações de sais em solos agrícolas são mais notáveis em áreas irrigadas, com maior ocorrência nas regiões áridas e semiáridas, uma vez que estas apresentam alta concentração de sais naturalmente (DIAS et al., 2011).

Entre os efeitos nocivos dos sais sobre as plantas citamse diminuição do potencial osmótico, efeito toxico de íons específicos, nutricional e indiretos devido as alterações físicas e químicas no solo. Estes efeitos refletem em sérios prejuízos tanto nos diversos processos fisiológicos e bioquímicos. A redução na disponibilidade de água para os vegetais o estresse salino afeta diretamente as trocas gasosas, culminando na redução do crescimento, desenvolvimento e produção das culturas (NEVES et al., 2009).

Nesse contexto, Brito et al. (2008) relatam, que a viabilização do uso de água de baixa qualidade e de solos salinos é possível por meio do cultivo de genótipos de elevada tolerância a esse fator abiótico. No entanto, isso depende do desenvolvimento de cultivares mais tolerantes à salinidade, fato que exige o desenvolvimento de estudos para avaliação do efeito da salinidade sobre aspectos da fisiologia, crescimento e produção da planta, visando identificar genótipos que melhor se adequem a tais fatores.

A utilização de cultivares melhoradas geneticamente com o objetivo de aumentar a produtividade, a adaptabilidade e a estabilidade da produção, como também aumentar a resistência a altas temperaturas e estresses hídricos, tem sido muito comum, mas não se sabe ao certo até que ponto os novos genótipos são resistentes (FREIRE FILHO, et al., 2005).

Tendo em vista a importância econômica do feijão-caupi e dos problemas causados pela salinidade, se faz necessário estudos que permitam conhecer formas de minimizar esses efeitos, tornando possível, práticas como o aproveitamento das águas salinizadas em genótipos tolerantes à salinidade, sem prejuízo de redução em crescimento, desenvolvimento e produtividade da cultura. Diante disso, o objetivou-se avaliar as características produtivas de genótipos de feijão-caupi irrigados com água salina.

\section{MATERIAL E MÉTODOS}

A pesquisa foi desenvolvida no período de Outubro a Dezembro no ano de 2014, em ambiente protegido (casa de vegetação) da Universidade Federal de Campina Grande, nas instalações da Unidade Acadêmica de Engenharia Agrícola/UFCG, Centro de Tecnologia e Recursos Naturais, em Campina Grande, PB.

Utilizou-se o delineamento experimental inteiramente casualizado, em esquema fatorial $2 \times 5$ com 4 repetições, sendo os tratamentos compostos de dois níveis de condutividade elétrica da água(A1 - água de abastecimento com $0,8 \mathrm{dSm}^{-1}$ e $\mathrm{A} 2$ - solução salina $4,8 \mathrm{dSm}^{-1}$ ) e cinco genótipos de feijão-caupi (G1 - MNC04-762F-9, G2 MNC04-762F-3, G3 - MNC04-762F-21, G4 - MNC04-769F62 e G5 - MNC04-765F-153).

As plantas foram conduzidas em vasos de polietileno, com $20 \mathrm{Kg}$ de solo esterilizado, e adubado, de acordo com Novais et al.(1991), para ambiente controlado em vasos. Os vasos foram colocados em capacidade de campo, com água de abastecimento, semeando-se 3 sementes por vaso, a uma profundidade de $2 \mathrm{~cm}$. Com 10 dias após a semeadura foi realizado o primeiro desbaste, deixando-se apenas duas plantas em cada vaso, aquela de maior vigor, o segundo desbaste ocorreu aos 12 dias após a semeadura (DAS), com também a irrigação com água salina, colocando-se manualmente o volume necessário para manter o solo próximo à capacidade de campo, conforme o tratamento. A solução de água salina para irrigação foi preparada a partir do sal $\mathrm{NaCl}$, feitas as avaliações de condutividade elétrica (CE) das água de abastecimento e salina, até alcançarem o valor desejado. Aos 75 DAS, no fim do ciclo do feijão-caupi, os genótipos foram avaliados após a colheita, quanto ao número de vagens por planta (NVP), comprimento da vagem por planta (CVP), número de grãos por vagem (NGV), número de grãos por planta (NGP) e peso dos grãos por planta (PGP). Os dados obtidos foram submetidos à análise de variância pelo teste ' $F$ ' e nos casos de significância com o teste de Tukey a $5 \%$ de probabilidade para a comparação das médias. Utilizando o programa Sisvar 5.3.

\section{RESULTADOS E DISCUSSÃO}

Conforme o resumo da analise de variância (Tabela 1), observa-se que houve efeito significativo $(\mathrm{p}<0,05)$ dos níveis salino da água de irrigação sobre número de vagens por planta (NVP), comprimento de vagem por planta (CVP), número de grãos por vagem (NGV), número de grãos por planta (NGP) e peso de grãos por planta (PGP) de genótipos de feijão-caupi. Resultados semelhantes foram encontrados por Santana et al. (2003) com o feijoeiro cultivar ESAL 686, onde a produção foi reduzida com presença de sais na água de irrigação.

Os resultados encontrados estão associados aos efeitos da salinidade da água de irrigação sobre a fisiologia e desenvolvimento das plantas, afetando diretamente as características de produção avaliadas em diferentes genótipos de feijão-caupi. 
Tabela 1 - Resumo da análise de variância parao número de vagens por planta (NVP), comprimento de vagem por planta (CVP), número de grãos por vagem (NGV), número de grãos por planta (NGP) e peso de grãos por planta (PGP) em genótipos de feijão-caupi sob irrigação com água salina. Campina Grande, 2014.

\begin{tabular}{ccccccc}
\hline & & \multicolumn{3}{c}{ Quadrado Médio } \\
\cline { 3 - 7 } FV & GL & NVP & CVP & NGV & NGP & PGP \\
\hline Salinidade (S) & 1 & $81,2250^{*}$ & $184,9000^{*}$ & $260,10^{*}$ & $20784,25^{*}$ & $714,025^{*}$ \\
Genótipos (G) & 4 & $1,0205^{\mathrm{ns}}$ & $2,8500^{\mathrm{ns}}$ & $5,1875^{\mathrm{ns}}$ & $530,930^{\mathrm{ns}}$ & $7,6625^{\mathrm{ns}}$ \\
S x G & 4 & $5,600^{\mathrm{ns}}$ & $2,2750^{\mathrm{ns}}$ & $4,0375^{\mathrm{ns}}$ & $764,087^{* *}$ & $5,7125^{\mathrm{ns}}$ \\
Erro & 27 & 2,4361 & 4,0070 & 7,3181 & 220,4435 & 8,9175 \\
CV (\%) & & 21,90 & 12,17 & 27,05 & 17,44 & \\
\hline
\end{tabular}

ns, ${ }^{* *}, *$ respectivamente não significativo, a $\mathrm{p}<0,01$ e $\mathrm{p}<0,05$

Verifica-se para número de vagens por planta (Figura 1), de acordo com o teste de médias, onde houve efeito significativo apenas para o fator de tratamento, o genótipo G4 alcançou maior média $(6,25)$ com o tratamento Água 1 (irrigação com água de abastecimento), no entanto, obteve menor média no tratamento com uso de água salina na irrigação, obtendo um redução de $72 \%$. Já os dados obtidos do genótipo G3 apresenta menor diferença entre os tratamentos (Água 1 e Água 2). Observa-se com os dados obtidos que o aumento da salinidade da água de irrigação afetou a emissão de ramos reprodutivos, sendo um fator preponderante à redução da produtividade.

A redução na produtividade promovida pela salinidade já foi observada em outras cultivares dessa espécie. Segundo Assis Júnior et al. (2007) a irrigação com níveis de salinidade de $5 \mathrm{dS} \mathrm{m}^{-1}$ reduziu a produtividade do feijão-caupi em $36 \%$, quando comparado à irrigação com água de baixa salinidade.

Esses efeitos estão associados aos efeitos osmóticos, tóxicos e nutricionais do estresse salino, que afetam a assimilação líquida de $\mathrm{CO}_{2}$, inibem a expansão foliar e aceleram a senescência de folhas maduras, reduzindo, consequentemente, a área destinada ao processo fotossintético e a produção total de fotoassimilados (LACERDA et al., 2003).

Figura 1. Teste de Médias para número de vagens por planta de genótipos de feijão-caupi irrigados com água salina. Campina Grande, PB, 2014.

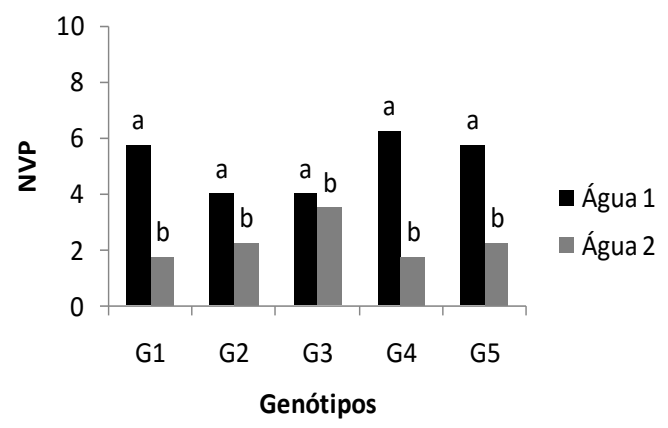

Para a variável comprimento de vagens por plantas (Figura 2), os genótipos (G1, G2, G3,G4 e G5) obtiveram médias equivalentes com exceção do genótipo G4, com o uso de água de abastecimento na irrigação $0,8 \mathrm{dSm}^{-1}$ (Agua 1). No entanto a água de condutividade elétrica de $4,8 \mathrm{dSm}^{-1}$ (Água 2) ocasionou redução nesta variável para todos os genótipos estudados, sendo os genótipos G1 e G4 os menos afetados. Segundo Freire Filho et al (2005), o comprimento médio de vagem com valor comercial é entorno de $18 \mathrm{~cm}$, de acordo com os resultados encontrados, todos os genótipos com o tratamento de água salina não possui valor comercial, devido a apresentarem médias inferiores ao comprimento da vagem com valor comercial.

Figura 2. Teste de Médias para o comprimento de vagens por planta de genótipos de feijão-caupi irrigados com água salina. Campina Grande, PB, 2014.

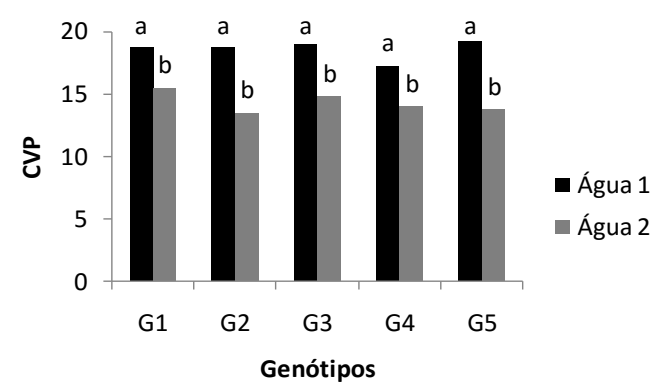

Na Figura 3 houve efeito significativo $(p<0,05)$ para o número de grãos por vargem $(\mathrm{NGV})$. Para as plantas submetidas ao tratamento com Água 1, se destacam com as maiores médias os genótipos G5 e G3 com 14,50 e 13,50 grãos por vargem respectivamente. Com a utilização na irrigação da Água 2, ocorreu um redução de mais $31 \%$, sendo o G1, o genótipo que apresentou menor influencia quanto ao tratamento com água salina.

Neves et al. (2010), avaliando a cultivar EPACE 10, mostrou que a aplicação com água de $5 \mathrm{dS} \mathrm{m}^{-1}$ diminuiu a produtividade em $40 \%$, quando comparado ao tratamento com água de baixa salinidade. Esses efeitos estão associados aos processos osmóticos, tóxicos e nutricionais do estresse salino, que afetam a assimilação líquida de $\mathrm{CO} 2$, inibe a expansão foliar e aceleram a senescência de folhas maduras, reduzindo, consequentemente, a área destinada ao processo fotossintético e a produção total de fotoassimilados, diminuindo assim, a produção de grãos da cultura (LACERDA et al., 2006, SOUSA et al., 2010).

Figura 3. Teste de Médias para o número de grãos por vargem de genótipos de feijão-caupi irrigados com água salina. Campina Grande, PB, 2014.

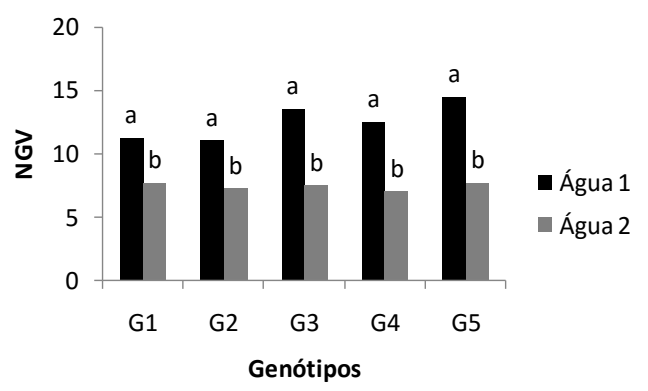


Para a variável NGP de genótipos de feijão-caupi, observou-se interação entre os fatores estudados, os genótipos foram avaliados com a salinidade da água de irrigação, para a variável de produção em função dos tratamentos. Para o tratamento Água 1, os genótipos que tiveram maiores médias foram G5 e G4 (78,50 e 78 grãos por planta) respectivamente. Já para as plantas irrigadas com Água 2 obtiveram respectivas reduções de 88 e $84 \%$ na produção de grãos por planta, sendo o G5 o mais afetado na presença da água salina para a irrigação.

A salinidade afeta negativamente a absorção de água pelas raízes. A presença de sais a solução do solo acarreta em uma diminuição do potencial hídrico externo (Epstein; Bloom, 2006).

Figura 4. Teste de Médias para o número de grãos por planta de genótipos de feijão-caupi irrigados com água salina. Campina Grande, PB, 2014.

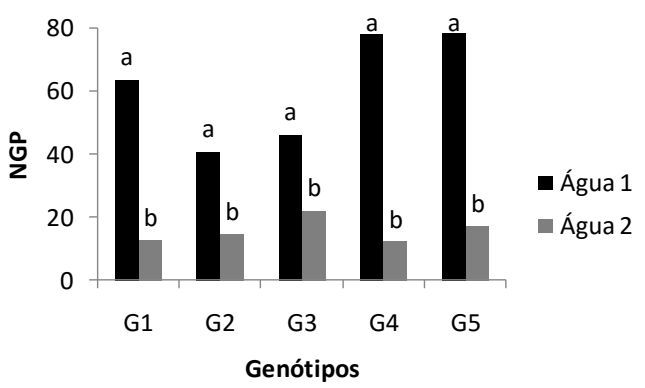

Pode-se observar na figura 5, o teste de comparação das médias Tukey $(\mathrm{p}<0,05)$, para o peso de grãos por planta em função dos tratamentos usados, onde a água de irrigação de abastecimento (Água 1) possui maiores média em relação a todas os genótipos avaliados, os genótipos que alcançaram as maiores médias foram o G1 com 12,50g e G5 com 11g. Na presença de salinidade, na água de irrigação o genótipo que obteve maior média foi o $\mathrm{G} 3 \mathrm{com}$ o peso de $3,50 \mathrm{~g}$ de grãos por planta.

Figura 5. Teste de Médias para o peso dos grãos por planta de genótipos de feijão-caupi irrigados com água salina. Campina Grande, PB, 2014.

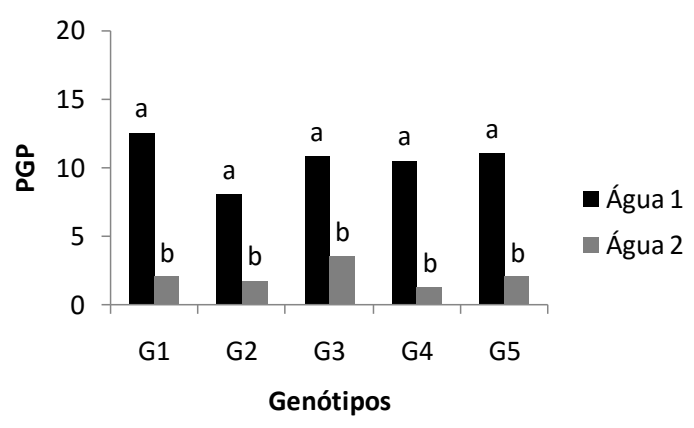

\section{CONCLUSÕES}

Irrigação com CEa acima de $0,8 \mathrm{dS} \quad \mathrm{m}^{-1}$ afeta negativamente as variáveis estudadas.

Houve interação entre os fatores, Salinidade da água de irrigação e Genótipos de feijão-caupi, para a variável número de grãos por planta.

\section{REFERÊNCIAS BIBLIOGRÁFICAS}

ASSIS JÚNIOR J. O.; LACERDA C. F.; SILVA F. B.; FRANCISCO SILVA L. B.;BEZERRA M. A.; GHEYI H. R. Produtividade do feijão-de-corda e acúmulo de sais no soloem função da fração de lixiviação e da salinidade da água de irrigação. Revista Brasileira de Engenharia Agrícola, v. 27, n. 3, p.702-713, 2007.

BRITO, M.E.B.; FERNANDES, P.D.; GHEYI, H.R.; MELO, A.S.; CARDOSO, J.A.F.; SOARES FILHO, W.S. Sensibilidade de variedades e híbridos de citrange à salinidade na formação de porta-enxertos. Revista Brasileira de Ciências Agrárias, v.3, n.4, p.343353,2008 .

DIAS, T. J.; CAVALCANTE, L. F.; LEON, M. J.; SANTOS, G. P.; ALBUQUERQUE, R. P. F. Produção do maracujazeiro e resistência mecânica do solo com biofertilizante sob irrigação com águas salinas. Revista Ciência Agronômica, v. 42, n. 3, p. 644-65, 2011.

EPSTEIN, E.; BLOOM, A. J. Nutrição mineral de plantas: princípios e perspectivas. Londrina: Editora Planta. 403p, 2006.

FREIRE FILHO, F. R.; RIBEIRO, V. Q.; BARRETO, P. D. SANTOS, A. A. Melhoramento genético. In: Feijão caupi: avanços tecnológicos. Brasília: EMBRAPA, 2005. Cap.1. p. 29-92.

FREIRE FILHO, F. R.; RIBEIROET, V. Q.;ROCHA, M. M.; SILVA, K. J. D. Feijão Caupi no Brasil: produção, melhoramento genético, avanços e desafios. Embrapa Meio Norte, Teresina, 84 p. 2011.

LACERDA, C. F.; ASSIS JUNIOR J. O; LEMOS FILHO L. C. A; GUIMARÃES, F. V. A;OLIVEIRA T. S; GOMES FILH, E; PRISCO J. T; BEZERRA M. A. Morphophysiological responses of cowpea leaves to salt stress. Brazilian Journal Plant Physiology., v. 18, p. 455-465, 2006.

LACERDA, C.F.; CAMBRAIA, J.; CANO, M.A.O.; RUIZ, H.A.; PRISCO, J.T. Solute accumulation and distribution during shoot and leaf development in two sorghum genotypes under salt stress. Environmental and Experimental Botany, Paris, v.49, n.2, p.107-20, 2003.

NASCIMENTO, H. T. S. Feijão-Caupi no Brasil: produção, melhoramento genético, avanços e desafios. Brasília: Embrapa, 2011.

NEVES, A. L. R.; LACERDA, C. F.; GUIMARÃES, F. V. A.; HERNANDEZ, F. F. F.;SILVA, F. B.; PRISCO, J. T.; GHEYI, H. R. Acumulação de biomassa e extração de nutrientes por plantas de feijão-de-cordas irrigadas com água salina em diferentes estádios de desenvolvimento. Ciência Rural, v. 39, p.758-765, 2009.

NEVES, A.L.R.; GUIMARÃES, F. V. A.; LACERDA, C. F.; SILVA, F. B. Tamanho e composição mineral de 
sementes de feijão-de-corda irrigado com água salina emdiferentes estádios de desenvolvimento. Revista Ciência Agronômica, Fortaleza, v.39, p.569-574, 2008. Disponível em: <http:// www.ccarevista.ufc.br/seer/index.php/ccarevista/article/ viewle/ 389/285>. Acesso em: 26 abr. 2015.

NOVAIS, R .J.; NEVES, J. C. L.; BARROS, N. F.Ensaios em ambiente controlado. In: OLIVEIRA, A. J. de.; GARRIDO, W. E.; ARAÚJO, J. D.; LOURENÇO, L.
Métodos de pesquisa em fertilidade do solo. Brasília: Embrapa, p.189-254, 1991.

SOUSA, G. G.; LACERDA, C. F.; CAVALCANTE, L. F.; GUIMARÃES, F. V. A.; BEZERRA, M. E. J.; SILVA, G. L. Nutrição mineral e extração de nutrientes de planta de milho irrigada com água salina. Revista Brasileira d de Engenharia Agrícola e Ambiental, v.14, p.11431151, 2010. 